International Journal of Pure and Applied Mathematics

Volume 103 No. 2 2015, 281-293

ISSN: 1311-8080 (printed version); ISSN: 1314-3395 (on-line version)

url: http://www.ijpam.eu

doi: http://dx.doi.org/10.12732/ijpam.v103i2.13

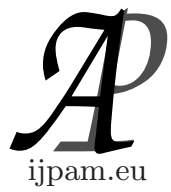

\title{
A COMMON FIXED POINT THEOREM FOR FOUR SELF MAPS IN CONE RECTANGULAR METRIC SPACE UNDER KANNAN TYPE CONTRACTIONS
}

\author{
M. Rangamma ${ }^{1}$, P. Mallikarjun $\operatorname{Reddy}^{2} \S$ \\ ${ }^{1,2}$ Department of Mathematics \\ College of Science \\ Osmania University \\ Hyderabad, 500007, Telangana, INDIA
}

\begin{abstract}
The purpose of this paper is to establish a common fixed point theorem for four self mappings which satisfy Kannan type contractive conditions in cone rectangular metric space.
\end{abstract}

AMS Subject Classification: 47H10, 54H25

Key Words: cone rectangular metric space, common fixed point theorem, coincidence point, contractive condition

\section{Introduction and Preliminaries}

Recently, Huang and Zhang [5] introduced the notion of cone metric spaces. They have replaced real number system by an ordered Banach space and established some fixed point theorems for contractive type mappings in a normal cone metric space. The study of fixed point theorems in such spaces is followed by some other mathematicians, see [1], [4], [9], [11], [14]. In 2009, Azam, Ar-

Received: April 30, 2015

(C) 2015 Academic Publications, Ltd.

$\S$ Correspondence author url: www.acadpubl.eu 
shad and Beg [2] introduced the notion of cone rectangular metric spaces. They have replaced triangular inequality by a rectangular inequality and proved fixed point theorem for Banach contraction in cone rectangular metric space. Several authors proved some fixed point theorems in such spaces, see [5], [8], [10], [12]. In 2009, Jleli, Samet [5] extended the Kannan's fixed point theorem in a complete normal cone rectangular metric space. In 2012, R. A. Rashwan and S. M. Saleh [12] have proved common fixed point theorems for two self mappings in cone rectangular metric space. In this paper, we prove a common fixed point theorem for four self mappings which satisfy Kannan type contractive conditions in cone rectangular metric space. Our result generalizes and extends the result of Jleli et el. [5] for four self mappings in a cone rectangular metric space.

First, we recall some standard definitions and other results that will be needed in the sequel.

Definition 1.1. (see [4]) A subset $\mathrm{P}$ of a real Banach space $\mathrm{E}$ is called a cone if it has following properties:

(1) $\mathrm{P}$ is nonempty, closed and $P \neq\{\theta\}$;

(2) $a, b \in R, a, b \geq 0, x, y \in P$ implies $a x+b y \in P$;

(3) $\mathrm{P} \cap(-\mathrm{P})=\{\theta\}$.

For a given coneP $\subseteq \mathrm{E}$, we can define a partial ordering $\leq$ on $\mathrm{E}$ with respect to $\mathrm{P}$ by $x \leq y$ if and only if $y-x \in P$. We shall write $x<y$ if $x \leq y$ and $x \neq y$, while $x<<y$ will stands for $y-x \in \operatorname{int}(\mathrm{P})$, where int $(\mathrm{P})$ denotes the interior of $\mathrm{P}$.

Definition 1.2. (see [4]) The cone $\mathrm{P}$ is called normal if there is a number $k>1$ such that for all $x, y \in E, 0 \leq x \leq y$ implies $\|x\| \leq k\|y\|$.

The least positive number $k$ satisfying the above condition is called the normal constant of $\mathrm{P}$.

Proposition 1.3. (see [14]) Let $(X, d)$ be a cone metric space with cone $P$ is not necessary to be normal. Then for $a, c, u, v, w \in E$, we have

(1) If $a \leq \lambda a$ and $\lambda \in[0,1)$, then $a=\theta$.

(2) If $\theta \leq u \ll c$, for each $\theta \ll c$, then $u=\theta$.

(3) If $u \leq v$ and $v \ll w$, then $u \ll w$. 
Definition 1.4. (see [4]) Let $\mathrm{X}$ is a non empty set, $\mathrm{E}$ is a real Banach space and $\mathrm{P}$ is a cone in $\mathrm{E}$ with int $\mathrm{P} \neq \Phi$ and $\leq$ is a partial ordering with respect to P. Suppose the mapping $d: \mathrm{X} \times \mathrm{X} \rightarrow \mathrm{E}$ satisfies:

(1) $\theta \leq d(x, y)$, for all $x, y \in X$ and $d(x, y)=\theta$ if and only if $x=y$;

(2) $d(x, y)=d(y, x)$, for all $x, y \in X$;

(3) $d(x, y) \leq d(x, z)+d(z, y)$, for all $x, y, z \in X$.

Then $d$ is called a cone metric on $\mathrm{X}$ and $(\mathrm{X}, \mathrm{d})$ is called a cone metric space.

Definition 1.5. (see [2]) Let $\mathrm{X}$ is a non empty set, $\mathrm{E}$ is a real Banach space and $\mathrm{P}$ is a cone in $\mathrm{E}$ with int $\mathrm{P} \neq \Phi$ and $\leq$ is a partial ordering with respect to $\mathrm{P}$. Suppose the mapping $d: \mathrm{X} \times \mathrm{X} \rightarrow \mathrm{E}$ satisfies:

(1) $\theta \leq d(x, y)$, for all $x, y \in X$ and $d(x, y)=\theta$ if and only if $x=y$;

(2) $d(x, y)=d(y, x)$, for all $x, y \in X$;

(3) $d(x, y) \leq d(x, w)+d(w, z)+d(z, y)$, for all $x, y \in X$ and for all distinct points $w, z \in X-\{x, y\}$ [rectangular inequality].

Then $d$ is called a cone rectangular metric on $\mathrm{X}$ and $(\mathrm{X}, \mathrm{d})$ is called a cone rectangular metric space.

Definition 1.6. (see [2]) Let $(\mathrm{X}, \mathrm{d})$ be a cone rectangular metric space. Let $\left\{x_{n}\right\}$ be a sequence in (X,d) and $x \in X$. If for every $c \in E$, with $\theta \ll c$ there is $n_{0} \in N$ such that for all $n>n_{0}, d\left(x_{n}, x\right) \ll c$, then $\left\{x_{n}\right\}$ is said to be convergent, $\left\{x_{n}\right\}$ converges to $x$ and $x$ is the limit of $\left\{x_{n}\right\}$. We denote this by $\lim _{n \rightarrow \infty} x_{n}=x$ or $x_{n} \rightarrow x$, as $n \rightarrow \infty$.

Definition 1.7. (see [2]) Let (X, d) be a cone rectangular metric space. Let $\left\{x_{n}\right\}$ be a sequence in (X,d). If for every $c \in E$, with $\theta \ll c$ there is $n_{0} \in N$ such that for all $m, n>n_{0}, d\left(x_{n}, x_{m}\right) \ll c$, then $\left\{x_{n}\right\}$ is called a Cauchy sequence in $(\mathrm{X}, \mathrm{d})$.

Definition 1.8. (see [2]) Let (X, d) be a cone rectangular metric space. If every Cauchy sequence is convergent in $(X, d)$, then $(X, d)$ is called a complete cone rectangular metric space.

Lemma 1.9. (see [2]) Let $(X, d)$ be a cone rectangular metric space and $P$ be a normal cone with a normal constant $k$. Let $\left\{x_{n}\right\}$ be a sequence in $X$. Then $\left\{x_{n}\right\}$ converges to $x$ if and only if $\left\|d\left(x_{n}, x\right)\right\| \rightarrow 0$, as $n \rightarrow \infty$. 
Lemma 1.10 (see [2]) Let $(X, d)$ be a cone rectangular metric space, $P$ be a normal cone with a normal constant $k$. Let $\left\{x_{n}\right\}$ be a sequence in $X$. Then $\left\{x_{n}\right\}$ is a Cauchy sequence if and only if $\left\|d\left(x_{n}, x_{m}\right)\right\| \rightarrow 0$, as $n, m \rightarrow \infty$.

Definition 1.11. (see [7]) A self map T: $\mathrm{X} \rightarrow \mathrm{X}$ on a metric space (X, d) is called Kannan contraction if for all $x, y \in \mathrm{X}$, there exists $\lambda \in[0,1 / 2)$ such that

$$
d(T x, T y) \leq \lambda[d(x, T x)+d(y, T y)] .
$$

Definition 1.12. (see [12]) Let $\mathrm{T}$ and $\mathrm{S}$ are self maps of a nonempty set $\mathrm{X}$. If $w=T x=S x$, for some $x \in \mathrm{X}$, then $x$ is called a coincidence point of $\mathrm{T}$ and $\mathrm{S}$ and $w$ is called a point of coincidence of $\mathrm{T}$ and $\mathrm{S}$.

Definition 1.13. (see [14]) Two self mappings $\mathrm{T}$ and $\mathrm{S}$ are said to be weakly compatible if they commute at their coincidence points, that is, $T x=S x$ implies that $T S x=S T x$.

\section{Main Results}

In this section we establish a common fixed point theorem for four self mappings in cone rectangular metric space under Kannan type contractive conditions.

Theorem 2.1. Let $(X, d)$ be a cone rectangular metric space, $P$ be a normal cone with normal constant $k$ and let the mappings $S, T, U$ and $V: X \rightarrow$ $X$ satisfy the following:

(1) $d(S x, T y) \leq \lambda[d(S x, U x)+d(T y, V y)]$,

(2) $d(S x, S y) \leq \lambda[d(S x, U x)+d(S y, U y)]$,

(3) $d(T x, T y) \leq \lambda[d(T x, V x)+d(T y, V y)]$,

for all $x, y \in X$, where $\lambda \in[0,1 / 2)$. If $S(X) \subseteq V(X), T(X) \subseteq U(X)$ and one of $S(X), T(X), U(X)$ or $V(X)$ is a complete subspace of $X$, then the pairs (S, $U)$, and $(T, V)$ have a unique point of coincidence in $X$. Moreover, if $(S, U)$ and $(T, V)$ are weakly compatible pairs then $S, T, U$ and $V$ have a unique common fixed point in $X$.

Proof. Let $x_{0}$ be any arbitrary point of $\mathrm{X}$. Since, $\mathrm{S}(\mathrm{X}) \subseteq \mathrm{V}(\mathrm{X})$ andT $(\mathrm{X}) \subseteq$ $\mathrm{U}(\mathrm{X})$, starting with $x_{0}$ we define the sequence $\left\{y_{n}\right\}$ such that

$$
y_{2 n}=S x_{2 n}=V x_{2 n+1},
$$


and $y_{2 n+1}=T x_{2 n+1}=U x_{2 n+2}$, for all $n=0,1,2, \ldots$.

Suppose that $y_{m}=y_{m+1}$, for some $m \in N$.

If $m=2 k$, then $y_{2 k}=y_{2 k+1}$, for some $k \in N$, then from (1) we get

$$
\begin{aligned}
d\left(y_{2 k+2}, y_{2 k+1}\right) & =d\left(S x_{2 k+2}, T x_{2 k+1}\right) \\
& \leq \lambda\left[d\left(S x_{2 k+2}, U x_{2 k+2}\right)+d\left(T x_{2 k+1}, V x_{2 k+1}\right)\right] \\
& =\lambda\left[d\left(y_{2 k+2}, y_{2 k+1}\right)+d\left(y_{2 k+1}, y_{2 k}\right)\right]
\end{aligned}
$$

i.e.

$$
d\left(y_{2 k+2}, y_{2 k+1}\right) \leq \lambda d\left(y_{2 k+2}, y_{2 k+1}\right)
$$

which implies that, $y_{2 k+2}=y_{2 k+1}$.

Similarly, we can deduce that $y_{2 k+2}=y_{2 k+3}=y_{2 k+4} \ldots$.

Hence $y_{n}=y_{m}$, for all $n \geq m$.

Thus $\left\{y_{n}\right\}$ is a Cauchy sequence in $\mathrm{X}$ in this case.

Assume that, $y_{n} \neq y_{n+1}$, for all $\mathrm{n} \in \mathrm{N}$.

Then from (1) it follows that,

$$
\begin{aligned}
d\left(y_{2 k}, y_{2 k+1}\right) & =d\left(S x_{2 k}, T x_{2 k+1}\right) \\
& \leq \lambda\left[d\left(S x_{2 k}, U x_{2 k}\right)+d\left(T x_{2 k+1}, V x_{2 k+1}\right)\right] \\
& =\lambda\left[d\left(y_{2 k}, y_{2 k-1}\right)+d\left(y_{2 k+1}, y_{2 k}\right)\right]
\end{aligned}
$$

which implies that

$$
d\left(y_{2 k}, y_{2 k+1}\right) \leq \mu d\left(y_{2 k-1}, y_{2 k}\right),
$$

for all $k \geq 1$, where $\mu=\frac{\lambda}{1-\lambda}<1$.

Also

$$
\begin{aligned}
d\left(y_{2 k+1}, y_{2 k+2}\right) & =d\left(T x_{2 k+1}, S x_{2 k+2}\right) \\
& \leq \lambda\left[d\left(S x_{2 k+2}, U x_{2 k+2}\right)+d\left(T x_{2 k+1}, V x_{2 k+1}\right)\right] \\
& =\lambda\left[d\left(y_{2 k+2}, y_{2 k+1}\right)+d\left(y_{2 k+1}, y_{2 k}\right)\right]
\end{aligned}
$$

which implies that

$$
d\left(y_{2 k+1}, y_{2 k+2}\right) \leq \mu d\left(y_{2 k}, y_{2 k+1}\right),
$$

for all $k \geq 1$, where $\mu=\frac{\lambda}{1-\lambda}<1$.

Using (4) and (5) we obtain

$$
\begin{aligned}
d\left(y_{2 k}, y_{2 k+1}\right) & \leq \mu d\left(y_{2 k-1}, y_{2 k}\right) \\
& \leq \mu^{2} d\left(y_{2 k-2}, y_{2 k-1}\right)
\end{aligned}
$$




$$
\leq \mu^{2 k} d\left(y_{0}, y_{1}\right)
$$

for all $k \geq 1$ and

$$
\begin{aligned}
d\left(y_{2 k+1}, y_{2 k+2}\right) & \leq \mu d\left(y_{2 k}, y_{2 k+1}\right) \\
\leq & \mu^{2} d\left(y_{2 k-1}, y_{2 k}\right) \\
& \vdots \\
& \leq \mu^{2 k+1} d\left(y_{0}, y_{1}\right),
\end{aligned}
$$

for all $k \geq 1$.

From (6) and (7) we have

$$
d\left(y_{n}, y_{n+1}\right) \leq \mu^{n} d\left(y_{0}, y_{1}\right)
$$

for all $n \geq 1$.

Using (2), (8), the facts that $\lambda \leq \mu$, and $\mu<1$, we obtain

$$
\begin{aligned}
d\left(y_{2 k}, y_{2 k+2}\right) & =d\left(S x_{2 k}, S x_{2 k+2}\right) \\
& \leq \lambda\left[d\left(S x_{2 k}, U x_{2 k}\right)+d\left(S x_{2 k+2}, U x_{2 k+2}\right)\right] \\
& \leq \lambda\left[d\left(y_{2 k}, y_{2 k-1}\right)+d\left(y_{2 k+2}, y_{2 k+1}\right)\right] \\
& \leq \lambda\left[\mu^{2 k-1} d\left(y_{0}, y_{1}\right)+\mu^{2 k+1} d\left(y_{0}, y_{1}\right)\right] \\
& \leq \mu^{2 k} d\left(y_{0}, y_{1}\right)+\mu^{2 k+2} d\left(y_{0}, y_{1}\right) \\
& =\left(1+\mu^{2}\right) \mu^{2 k} d\left(y_{0}, y_{1}\right) \\
& \leq(1+\mu) \mu^{2 k} d\left(y_{0}, y_{1}\right)
\end{aligned}
$$

for all $k \geq 1$.

Using (3), (8), $\lambda \leq \mu$, and $\mu<1$, we get

$$
\begin{aligned}
d\left(y_{2 k+1}, y_{2 k+3}\right) & =d\left(T x_{2 k+1}, T x_{2 k+3}\right) \\
& \leq \lambda\left[d\left(T x_{2 k+1}, V x_{2 k+1}\right)+d\left(T x_{2 k+3}, V x_{2 k+3}\right)\right] \\
& \leq \lambda\left[d\left(y_{2 k+1}, y_{2 k}\right)+d\left(y_{2 k+3}, y_{2 k+2}\right)\right] \\
& \leq \lambda\left[\mu^{2 k} d\left(y_{0}, y_{1}\right)+\mu^{2 k+2} d\left(y_{0}, y_{1}\right)\right] \\
& \leq \mu^{2 k+1} d\left(y_{0}, y_{1}\right)+\mu^{2 k+3} d\left(y_{0}, y_{1}\right) \\
& =\left(1+\mu^{2}\right) \mu^{2 k+1} d\left(y_{0}, y_{1}\right)
\end{aligned}
$$




$$
\leq(1+\mu) \mu^{2 k} d\left(y_{0}, y_{1}\right)
$$

for all $k \geq 1$.

Therefore from (9) and (10) we obtain

$$
d\left(y_{n}, y_{n+2}\right) \leq(1+\mu) \mu^{n} d\left(y_{0}, y_{1}\right)
$$

for all $n \geq 1$.

For the sequence $\left\{y_{n}\right\}$, we consider $d\left(y_{n}, y_{n+p}\right)$ in two cases.

If $p$ is odd say $2 m+1$, for $m \geq 1$, then by the use of rectangular inequality and (8) we get

$$
\begin{aligned}
d\left(y_{n}, y_{n+2 m+1}\right) \leq & d\left(y_{n+2 m+1}, y_{n+2 m}\right)+d\left(y_{n+2 m}, y_{n+2 m-1}\right)+d\left(y_{n+2 m-1}, y_{n}\right) \\
\leq & d\left(y_{n+2 m}, y_{n+2 m+1}\right)+d\left(y_{n+2 m-1}, y_{n+2 m}\right)+d\left(y_{n+2 m-1}, y_{n+2 m-2}\right) \\
& +d\left(y_{n+2 m-2}, y_{n+2 m-3}\right)+\ldots+d\left(y_{n+2}, y_{n+1}\right)+d\left(y_{n+1}, y_{n}\right) \\
= & d\left(y_{n}, y_{n+1}\right)+d\left(y_{n+1}, y_{n+2}\right)+\ldots+d\left(y_{n+2 m-2}, y_{n+2 m-1}\right) \\
& +d\left(y_{n+2 m-1}, y_{n+2 m}\right)+d\left(y_{n+2 m}, y_{n+2 m+1}\right) \\
\leq & \mu^{n} d\left(y_{0}, y_{1}\right)+\mu^{n+1} d\left(y_{0}, y_{1}\right)+\mu^{n+2} d\left(y_{0}, y_{1}\right)+\ldots \\
& +\mu^{n+2 m-1} d\left(y_{0}, y_{1}\right)+\mu^{n+2 m} d\left(y_{0}, y_{1}\right) \\
= & {\left[1+\mu+\mu^{2}+\mu^{3}+\ldots+\mu^{2 m-1}+\mu^{2 m}\right] \mu^{n} d\left(y_{0}, y_{1}\right) } \\
\leq & \frac{\mu^{n}}{1-\mu} d\left(y_{0}, y_{1}\right), \quad \text { for all } n \geq 1, m \geq 1 .
\end{aligned}
$$

If $p$ is even say $2 m$, for $m \geq 1$, then by the use of rectangular inequality, (8) and (11) we get

$$
\begin{aligned}
d\left(y_{n}, y_{n+2 m}\right) \leq & d\left(y_{n+2 m}, y_{n+2 m-1}\right)+d\left(y_{n+2 m-1}, y_{n+2 m-2}\right)+d\left(y_{n+2 m-2}, y_{n}\right) \\
\leq & d\left(y_{n+2 m-1}, y_{n+2 m}\right)+d\left(y_{n+2 m-2}, y_{n+2 m-1}\right)+\ldots+d\left(y_{n+4}, y_{n+3}\right) \\
& +d\left(y_{n+3}, y_{n+2}\right)+d\left(y_{n+2}, y_{n}\right) \\
= & d\left(y_{n}, y_{n+2}\right)+d\left(y_{n+2}, y_{n+3}\right)+\ldots+d\left(y_{n+2 m-2}, y_{n+2 m-1}\right) \\
& +d\left(y_{n+2 m-1}, y_{n+2 m}\right) \\
\leq & (1+\mu) \mu^{n} d\left(y_{0}, y_{1}\right)+\left[\mu^{n+2} d\left(y_{0}, y_{1}\right)+\mu^{n+3} d\left(y_{0}, y_{1}\right)\right. \\
& \left.+\mu^{n+2 m-2} d\left(y_{0}, y_{1}\right)+\mu^{n+2 m-1} d\left(y_{0}, y_{1}\right)\right] \\
= & {\left[1+\mu+\mu^{2}+\mu^{3}+\ldots+\mu^{2 m-2}+\mu^{2 m-1}\right] \mu^{n} d\left(y_{0}, y_{1}\right) } \\
\leq & \frac{\mu^{n}}{1-\mu} d\left(y_{0}, y_{1}\right), \quad \text { for all } n \geq 1, m \geq 1 .
\end{aligned}
$$


Thus combining the above two cases we have

$$
d\left(y_{n}, y_{n+p}\right) \leq \frac{\mu^{n}}{1-\mu} d\left(y_{0}, y_{1}\right), \quad \text { for all } n \in N, p \in N
$$

Since, $\mathrm{P}$ is a normal cone with a normal constant $k$ and $0 \leq \mu<1$, we have

$$
\left\|d\left(y_{n}, y_{n+p}\right)\right\| \leq \frac{k \mu^{n}}{1-\mu}\left\|d\left(y_{0}, y_{1}\right)\right\| \rightarrow 0, \text { as } n \rightarrow \infty,
$$

i.e.

$$
\left\|d\left(y_{n}, y_{n+p}\right)\right\| \rightarrow 0, \text { as } n \rightarrow \infty, \quad \forall p \in N .
$$

Hence, $\left\{y_{n}\right\}$ is a Cauchy sequence in $\mathrm{X}$.

Suppose, $\mathrm{U}(\mathrm{X})$ is a complete subspace of $\mathrm{X}$, there exists $z \in U(X)$ such that $\lim _{n \rightarrow \infty} y_{2 n+1}=\lim _{n \rightarrow \infty} U x_{2 n+2}=z$. Consequently we find $x \in X$ such that $z=U x$. Then by using rectangular property and (2), we have

$$
\begin{aligned}
d(S x, z) & \leq d\left(S x, y_{2 n}\right)+d\left(y_{2 n}, y_{2 n+1}\right)+d\left(y_{2 n+1}, z\right) \\
& =d\left(S x, S x_{2 n}\right)+d\left(y_{2 n}, y_{2 n+1}\right)+d\left(y_{2 n+1}, z\right) \\
& \leq \lambda\left[d(S x, U x)+d\left(S x_{2 n}, U x_{2 n}\right)\right]+d\left(y_{2 n}, y_{2 n+1}\right)+d\left(y_{2 n+1}, z\right) \\
& =\lambda d(S x, z)+\lambda d\left(y_{2 n}, y_{2 n-1}\right)+d\left(y_{2 n}, y_{2 n+1}\right)+d\left(y_{2 n+1}, z\right),
\end{aligned}
$$

which implies

$$
\begin{aligned}
d(S x, z) \leq \frac{\lambda}{1-\lambda} d\left(y_{2 n}, y_{2 n-1}\right)+\frac{1}{1-\lambda}\left[d\left(y_{2 n}, y_{2 n+1}\right)+d\left(y_{2 n+1}, z\right)\right] & \\
& \text { for all } n \geq 1 .
\end{aligned}
$$

Since, $\mathrm{P}$ is a normal cone with a normal constant $k$ we have,

$$
\begin{aligned}
\|d(S x, z)\| \leq & \frac{k \lambda}{1-\lambda}\left\|d\left(y_{2 n}, y_{2 n-1}\right)\right\| \\
& \quad+\frac{k}{1-\lambda}\left[\left\|d\left(y_{2 n}, y_{2 n+1}\right)\right\|+\left\|d\left(y_{2 n+1}, z\right)\right\|\right] \rightarrow 0, \text { as } n \rightarrow \infty .
\end{aligned}
$$

i.e. $\|d(S x, z)\|=0$ or $S x=z$.

Therefore

$$
S x=U x=z .
$$

Since $z=S x \in S(X)$ and $S(X) \subseteq V(X)$, there exists $y \in X$ such that $z=V y$. 
Now,

$$
\begin{aligned}
d(T y, z) & \leq d\left(T y, y_{2 n}\right)+d\left(y_{2 n}, y_{2 n+1}\right)+d\left(y_{2 n+1}, z\right) \\
& =d\left(T y, S x_{2 n}\right)+d\left(y_{2 n}, y_{2 n+1}\right)+d\left(y_{2 n+1}, z\right) \\
& \leq \lambda\left[d\left(S x_{2 n}, U x_{2 n}\right)+d(T y, V y)\right]+d\left(y_{2 n}, y_{2 n+1}\right)+d\left(y_{2 n+1}, z\right) \\
& =\lambda\left[d\left(y_{2 n}, y_{2 n-1}\right)+d(T y, z)\right]+d\left(y_{2 n}, y_{2 n+1}\right)+d\left(y_{2 n+1}, z\right),
\end{aligned}
$$

which implies

$$
\begin{aligned}
& d(T y, z) \leq \frac{\lambda}{1-\lambda} d\left(y_{2 n-1}, y_{2 n}\right) \\
& \quad+\frac{1}{1-\lambda}\left[d\left(y_{2 n}, y_{2 n+1}\right)+d\left(y_{2 n+1}, z\right)\right] \text {, for all } n \geq 1 .
\end{aligned}
$$

Since, $\mathrm{P}$ is a normal cone with a normal constant $k$, we have

$$
\begin{aligned}
\|d(T y, z)\| \leq & \frac{k \lambda}{1-\lambda}\left\|d\left(y_{2 n-1}, y_{2 n}\right)\right\| \\
& \quad+\frac{k}{1-\lambda}\left[\left\|d\left(y_{2 n}, y_{2 n+1}\right)\right\|+\left\|d\left(y_{2 n+1}, z\right)\right\|\right] \rightarrow 0, \text { as } \mathrm{n} \rightarrow \infty
\end{aligned}
$$

i.e. $\|d(T y, z)\|=0$ or $T y=z$.

Therefore

$$
T y=V y=z \text {. }
$$

From (12) and (13), we say that the pairs (S, U), and (T, V) have a common point of coincidence $z$ in X.

Suppose the pairs $(\mathrm{S}, \mathrm{U})$, and $(\mathrm{T}, \mathrm{V})$ are weakly compatible mappings. Then by using (12) and (13) we get

$$
S z=S U x=U S x=U z=z_{1}
$$

and

$$
T z=T V y=V T y=V z=z_{2} .
$$

Using (1), (14) and (15), we obtain

$$
\begin{aligned}
d\left(z_{1}, z_{2}\right) & =d(S z, T z) \\
& \leq \lambda[d(S z, U z)+d(T z, V z)] \\
& =\lambda\left[d\left(z_{1}, z_{1}\right)+d\left(z_{2}, z_{2}\right)\right]=\theta
\end{aligned}
$$

or $d\left(z_{1}, z_{2}\right)=\theta$. 
That is $z_{1}=z_{2}$.

Therefore

$$
S z=T z=U z=V z .
$$

Now we have to prove that $T z=z$.

Using (1), (12) and (16) we get

$$
\begin{aligned}
d(z, T z) & =d(S x, T z) \\
& \leq \lambda[d(S x, U z)+d(T z, V z)] \\
& =\lambda[d(z, T z)+d(T z, T z)]
\end{aligned}
$$

That is $d(z, T z) \leq \lambda d(z, T z)$, which implies that $d(z, T z)=\theta$.

Hence $z=T z$, or $S z=T z=U z=V z=z$.

Thus $z$ is a common fixed point of $\mathrm{S}, \mathrm{T}, \mathrm{U}$ and $\mathrm{V}$.

For the uniqueness suppose that $z^{*}$ is another common fixed point of $\mathrm{S}, \mathrm{T}$, $\mathrm{U}$, and V. That is, $S z^{*}=T z^{*}=U z^{*}=V z^{*}=z^{*}$. Then:

$$
\begin{aligned}
d\left(z, z^{*}\right) & =d\left(S z, T z^{*}\right) \\
& \leq \lambda\left[d(S z, U z)+d\left(T z^{*}, V z^{*}\right)\right] \\
& =\lambda\left[d(S z, S z)+d\left(T z^{*}, T z^{*}\right)\right]=\theta
\end{aligned}
$$

which implies that $d\left(z, z^{*}\right)=\theta$.

Hence, $z=z^{*}$ and moreover $\mathrm{S}, \mathrm{T}, \mathrm{U}$ and $\mathrm{V}$ have a unique common fixed point in X. Similarly, if $\mathrm{S}(\mathrm{X}), \mathrm{T}(\mathrm{X})$ or $\mathrm{V}(\mathrm{X})$ is a complete subspace of $\mathrm{X}$, then we can easily prove that $\mathrm{S}, \mathrm{T}, \mathrm{U}$ and $\mathrm{V}$ have a unique common fixed point in $\mathrm{X}$.

To illustrate Theorem 2.1 we give the following example.

Example 2.2. Let $\mathrm{X}=\{1,2,3,4\}, \mathrm{E}=\mathrm{R}^{2}$ and $\mathrm{P}=\{(x, y): x, y \geq$ $0\}$ is a normal cone in $\mathrm{E}$, where $\mathrm{R}$ denotes set of all Real numbers. Define $\mathrm{d}: \mathrm{X} \times \mathrm{X} \rightarrow \mathrm{E}$ as follows:

$$
\left\{\begin{array}{l}
d(x, x)=\theta, \text { for all } x \in X \\
d(1,2)=d(2,1)=(3,9) \\
d(1,3)=d(3,1)=d(2,3)=d(3,2)=(1,3) \\
d(1,4)=d(4,1)=d(2,4)=d(4,2)=d(3,4)=d(4,3)=(4,12),
\end{array}\right.
$$

Then $(\mathrm{X}, \mathrm{d})$ is a complete cone rectangular metric space.

Now, we can define the mappings $\mathrm{S}, \mathrm{T}, \mathrm{U}$ and $\mathrm{V}: \mathrm{X} \rightarrow \mathrm{X}$ as follows:

$$
S(x)=3, \quad \text { for all } x \in X,
$$




$$
\begin{aligned}
& T(x)=\left\{\begin{array}{l}
3 \text { if } x \neq 4, \\
1 \text { if } x=4,
\end{array}\right. \\
& U(x)=\left\{\begin{array}{l}
2 \text { if } x=1, \\
1 \text { if } x=2, \\
3 \text { if } x=3, \\
4 \text { if } x=4,
\end{array}\right.
\end{aligned}
$$

It is clear that, $\mathrm{S}(\mathrm{X}) \subseteq \mathrm{V}(\mathrm{X}), \mathrm{T}(\mathrm{X}) \subseteq \mathrm{U}(\mathrm{X}), \mathrm{S}$ and $\mathrm{U}$ are weakly compatible mappings. Note that, the Kannan type contractive conditions (1), (2) and (3) of Theorem 2.1 are satisfied if $\lambda=1 / 4$.

Hence, all the conditions of Theorem 2.1 are satisfied and 3 is a unique common fixed point of $\mathrm{S}, \mathrm{T}, \mathrm{U}$ and $\mathrm{V}$.

Corollary 2.3. Let $(X, d)$ be a cone rectangular metric space, $P$ be a normal cone with normal constant $k$ and let the mappings $S, T$ and $U: X \rightarrow X$ satisfy the following:

(1) $d(S x, T y) \leq \lambda[d(S x, U x)+d(T y, U y)]$,

(2) $d(S x, S y) \leq \lambda[d(S x, U x)+d(S y, U y)]$,

(3) $d(T x, T y) \leq \lambda[d(T x, U x)+d(T y, U y)]$,

for all $x, y \in X$, where $\lambda \in[0,1 / 2)$. If $S(X) \cup T(X) \subseteq U(X)$ and if $U(X)$ or $S(X) \cup T(X)$ is a complete subspace of $X$, then the pairs $(S, U)$ and ( $T$, $U)$ have a unique point of coincidence in $X$. Moreover, if $(S, U)$ and $(T, U)$ are weakly compatible pairs then $S, T$ and $U$ have a unique common fixed point in $X$.

Proof. If we put $\mathrm{V}=\mathrm{U}$, in Theorem 2.1, then we obtain the corollary.

\section{Acknowledgments}

The authors are grateful to the referees for careful reviewing of the article.

\section{References}

[1] M. Abbas and G. Jungck, Common fixed point results for non commuting mappings without continuity in cone metric spaces, Journal of Mathematical Analysis and Applications, 341, No. 1 (2008), 416-420. 
[2] A. Azam, M. Arshad, I. Beg, Banach contraction principle on cone rectangular metric spaces, Applicable Analysis and Discrete Mathematics, 3, No. 2 (2009), 236-241.

[3] S. Banach, Sur les operations dans les ensembles abstraits et leur application aux equations integrales, Fundamenta Mathematicae, 3, No. 1 (1922), 133-181.

[4] L.G. Huang, X. Zhang, Cone metric spaces and fixed point theorems of contractive mappings, Journal of Mathematical Analysis and Applications, 332, No. 2 (2007), 1468-1476.

[5] M. Jleli, B. Samet, The Kannan fixed point theorem in a cone rectangular metric space, Journal of Nonlinear Science and Applications, 2, No. 3 (2009), 161-167.

[6] G. Jungck, B.E. Rhoades, Fixed Points for set valued functions without continuity, Indian Journal of Pure and Applied Mathematics, 29, No. 3 (1998), 227-238.

[7] R. Kannan, Some results on fixed point, Bulletin Calcutta Mathematical Society, 60 (1968), 71 - 76.

[8] S. K. Malhotra, J. B. Sharma, S. Shukla, g-weak contraction in ordered cone rectangular metric spaces. The Scientific World Journal (2013a).

[9] S. K. Malhotra, S. Shukla, R. Sen, Some coincidence and common fixed point theorems in cone metric spaces, Bulletin of Mathematical Analysis and Applications, 4, No. 2 (2012), 64-71.

[10] S. K. Malhotra, S. Shukla, R. Sen, Some fixed point theorems for ordered reich type contractions in cone rectangular metric spaces, Acta Mathematica Universitatis Comenianae, 2 (2013b), 165-175.

[11] J. R. Morales, E. Rojas, Cone metric spaces and fixed point theorems of T-Kannan contractive mappings, International Journal of Mathematical Analysis, 4, No. 4 (2010), 175-184.

[12] R. A. Rashwan, S. M. Saleh, Some Fixed Point Theorems in Cone Rectangular Metric Spaces, Mathematica Aeterna, 2, No. 6 (2012), 573 - 587.

[13] S. Reich, Some remarks concerning contraction mappings, Canadian Mathematical Bulletin, 14, No. 1 (1971), 121 - 124. 
[14] S. Rezapour, R. Hamlbarani, Some notes on paper Cone metric spaces and fixed point theorems of contractive mappings, Journal of Mathematical Analysis and Applications, 345, No. 2 (2008), 719-724. 
